Session 2149

\title{
Planning and Execution: The Key to Developing a TC2K Quality Program
}

\author{
David S. Cottrell \\ Pennsylvania State University at Harrisburg
}

\section{Introduction}

This paper describes an ongoing process: the integration of the new ABET accreditation criteria for engineering technology (TC2K) into the School of Science, Engineering, and Technology at the Pennsylvania State University at Harrisburg. Currently three technology programs - Electrical Engineering, Mechanical Engineering, and Structural Design and Construction Engineering - are implementing outcomes based assessment processes that will lead to an atmosphere of continuous improvement and quality education. This paper documents the deliberate planning and the subsequent execution of a comprehensive plan designed to successfully transform the technology programs to a format consistent with the spirit and letter of the TC2K.

"Experience has shown that the way a change is implemented can influence the effectiveness of the transition as much as the contents of that change itself." ${ }^{6}$ The leadership within the School of Science, Engineering, and Technology at the Pennsylvania State University at Harrisburg recognized the importance of a road map to guide TC2K implementation as a prerequisite for success. Consequently, they developed a strategic, comprehensive plan with four distinct operational phases. The plan's operational concept focused on systematically revising the educational framework to support outcome/objective assessment and evaluation. Further, the program footing would promote academic programs characterized by a dynamic state of continuous process improvement consistent with TC2K. Viewed essentially as sequential in nature, the phases allowed the faculty in each of the three programs to control to some extent the rate of implementation. The fours phases include (1) awareness training for senior key personnel, (2) internal organizational assessment, (3) team building for process control and TC2K implementation, and (4) an action phase designed to perpetuate the program. This paper addresses each phase in turn and then concludes with some "lessons learned" from the process.

\section{Phase 1: Leadership Awareness}

The plan envisioned the "awareness phase" as an initial step toward creating an acute sensitivity in the senior faculty from both the targeted programs as well as the other faculty within the school. Initially, this took the form of "training the trainer" sessions for 
senior faculty achieved by sending selected faculty representatives from each program to formal seminars. ${ }^{1,2,3}$ These seminars were hosted or supported by the Technology Accreditation Committee (TAC) from ABET or by the Teaching and Learning Consortium from the Pennsylvania State University. The seminars typically lasted several days and featured both large lecture-type instruction and small group interactive sessions. The seminars proved highly effective in presenting the overall concepts encompassed by TC2K. However, the value of the seminars was found not in the theoretical discussions of continuous improvement but rather in the "hands on" training that served to equip the faculty with tools to implement the tenets of the TC2K. Seminar participants examined and simulated various methodologies for developing appropriate program objectives and outcomes, matched a wide variety of assessment techniques to hypothetical venues, and practiced iterative response cycles by performing outcome evaluations followed by hypothesizing specific actions to correct identified weaknesses while simultaneously reinforcing and sustaining strengths.

Participants during this phase of the plan developed an appreciation for the potential benefits possible through an application of the principles of continuous process improvement. Faculty returned to their campus with a clear vision of the intent behind ABET's shift to the new criteria and a keen perception of the potential gain of a program dedicated to continuous improvement. The awareness phase proved to be a catalyst for action as awareness sponsored collective efforts for a preliminary organizational assessment and naturally transitioned the School toward Phase II.

\section{Phase 2: Internal Organizational Assessment}

The seminars aided in creating a vision of the program's ultimate destination, but the TC2K implementation required the faculty to assess their current condition as a school and as academic programs. The organizational assessment initially targeted school personnel to inventory their prevailing attitudes toward the TC2K program shift. A series of informational briefings and presentations were conducted to collectively educate the faculty and staff from the school as well as the three programs individually. By design, each presentation evolved into an active dialogue where both the abstract concepts and the practical implementation issues were addressed. This proved to be an effective venue to assess the relative values, beliefs, opinions, and perceptions of the faculty and prepared the programs for a more formal internal audit. Input from the faculty was clearly mixed from excitement and enthusiasm to skepticism and resentment.

The organizational assessment as envisioned by the implementation plan also searched for objective measures that would initially establish the relative strengths and weaknesses of the programs. The ABET criteria furnished an initial framework for the assessment but the generic nature of the criteria made interpretation and direct application difficult. Programs immediately began to personalize the TC2K "a-k" outcomes ${ }^{4}$ in light of specific program goals and academic characteristics. Consequently, although the TC2K ABET criteria provided an initial backdrop for this early preliminary program assessment, the final result was that each program independently began the creative process of developing 
their own unique program goals, objectives, and outcomes. One program actually chose to develop their program outcomes independent of the TC2K "a-k" outcomes. ${ }^{4}$ Their initial efforts proved insightful but not fully complete when subsequent comparisons were made to the applicable TC2K criteria. Nevertheless, the two lists ultimately merged and became a fairly comprehensive list of program outcomes. Additionally, this same program also chose to restructure their outcomes in accordance with B. S. Bloom's taxonomy of education objectives that defines six major categories of the cognitive domain. ${ }^{7}$ This was an effective drill for the faculty within the program since it produced a set of outcomes that they could not only more readily relate to, but also one that clearly bore their "stamp of ownership." This particular set of outcomes from the Structural Design and Construction Engineering Technology Program is provided as an appendix to this paper.

With program outcomes in hand, Phase 2 of the plan continued with the programs auditing their curriculum in order to cross reference the program outcomes with course learning objectives. The resulting matrix provided a number of intriguing insights almost immediately. Some outcomes were covered in most if not all of the courses; these outcomes became "threads of continuity" within the programs. Other outcomes, however, were found in a smaller number of courses and, in a very few cases, in only one or two courses. In planning assessment activities later, this became a critical point of discussion due to the limited opportunity to formally assess student mastery, evaluate their performance, and apply any corrective measures in time to ensure student proficiency. Ultimately, this audit actually led in some instances to changes within courses to ensure adequate coverage, assessment, and evaluation of each program outcome.

\section{Phase 3: Team Building}

The third phase of team building commenced with the creation of an internal action committee to coordinate efforts across the program lines. Principle areas of focus included aiding programs in energizing their industry advisory committees and in identifying additional program constituents that might provide input in terms of perceived educational needs and expectations. Identifying constituents generally included the alumni, employees, industry representatives, other special interest groups depending on the specific program, and the faculty and staff themselves. The industry advisory committees for two of the programs were already viable and playing an active role in developing outcomes, objectives, surveys, etc. The third program struggled in this area to the extent that it continues to be an obstacle to their successful implementation of TC2K initiatives.

During this phase, the school director appointed the author as a special TC2K coordinator to monitor and assist in implementation of the new TC2K criteria. Each program further identified a representative that would serve on a committee chaired by the TC2K. This committee worked collectively across program boundaries to share lessons learned and to promote success. The TC2K coordinator answered directly to the School Director on matters pertaining to $\mathrm{TC} 2 \mathrm{~K}$ but worked directly with program chairmen as needed. The programs involved in this process were each relatively small, so the "team" 
infrastructure within the programs was kept to minimum. Meetings were scheduled routinely to discuss planning, organizing, staffing, and other related issues of common interest.

\section{Phase 4: The Action Phase}

The final implementation phase is the action phase - a dynamic, fluid execution of TC2K within the programs. By definition this phase is characterized by continuous training and support coupled with a constant drive to sense and address the recurring needs of the faculty as they work collectively to implement TC2K. The programs subsequently progressed to a point where the iterative cycles would commence with an appropriate level of assessment, evaluation, and response actions that are planned and executed to correct deficiencies or reinforce success. This sounds easy but in fact proved to be the most difficult part of the plan. Clearly a learning curve kicked in at this point as the programs relied on the organizational assessment and infrastructure of the earlier Phases of the plan and worked diligently toward TC2K implementation.

The School and Programs continue to refine the initial plans and assessment strategies, but resources to support the effort are tight. As the programs developed and crossreferenced program outcomes and objectives with the courses in the curriculum, they attempted to identify multiple opportunities that would permit collection of both objective test data as well as subjective survey data to support program assessment. Further, programs are developing metrics as standards to judge and evaluate students' mastery of the outcomes and objectives. Surveying alumni and industry representatives is not new, but creation of the surveys themselves in a manner that will provide some real input for assessment, evaluation, and response has proven to be challenging across the board for all three programs.

\section{Assessment of the Implementation Process}

On a personal note, as the TC2K coordinator during the last eighteen months, the author gained some insights pertaining to this deliberate process for implementing TC2K. The fallacy, of course, is that implementation is never complete but rather a process. The concept of continuous improvement defines a dynamic condition where programs must constantly strive to respond to failure and reinforce success with a dedication and timeless devotion. Nevertheless, the following discussion presents some lessons learned that are not necessarily new nor profound, but were definitely critical in our efforts to transform successfully into a school consistent with TC2K.

Teamwork: The key to our success to date can be summed up in this singular word. Certainly not original, the importance of a well-knit faculty in making the TC2K a reality has been documented by other institutions before this report. ${ }^{5}$ Our faculty enjoy a relationship characterized by mutual respect, cooperation, and assistance when needed. In our efforts to implement TC2K, two of the programs moved collectively through the process, but one program developed a tendency to rely heavily on one professor who 
became the "expert." This proved counterproductive as the level of effort to execute a compressive assessment/evaluation program cannot be handled by one person. It requires a collective, team effort to ensure success.

Commitment: Conversion to $\mathrm{TC} 2 \mathrm{~K}$ carried a tremendous learning curve that is apparently independent of tenure, academic rank, or experience. Faculty and staff have to buy in completely or the process will be tremendously more difficult. We had three programs going through this process concurrently. The varying degrees of commitment were quite easy to perceive and the corresponding effects on implementing TC2K were obvious: those who drug their feet, longing for a return to the "old ways," created internal obstacles that at times were almost insurmountable for those programs. On the other hand, a positive attitude went a long way to aid in creative applications and development of unique approaches to assessment and evaluation. It is a paradigm shift, but we have the ability to make the experience one of exciting academic discovery or bureaucratic misery. The adage "a house divided against itself cannot stand" is very true when dealing with $\mathrm{TC} 2 \mathrm{~K}$ implementation.

An Active Industry Advisory Committee: Again, this was critical for success. Our experience here had one program with an active committee that dated back some twenty years, contrasted with another advisory committee that had evolved into a dormant, almost non-existent body. The impact in both cases was quite phenomenal. The active committee aided in alumni and employer surveys, creation and refinement of program objectives and outcomes, application of assessment tools, and evaluation and development of corrective actions. They proved to be a credible, sounding board dedicated to developing and sustaining a strong, dynamic academic program as much the professors were themselves. The loss of this asset severely impacted the one program that was forced to expend critical resources out of necessity to generate a committee which then had to be "educated" as to expectations.

University Support: Teamwork and commitment must extent vertically throughout the organization. We were fortunate that the support we needed was there when we needed it, but we recognize the inherent problems that would have existed if development and implementation were left to program resources alone. Our program is quite small, and our implementation of TC2K continues to stretch our programs to the nth degree.

\section{Conclusion:}

This paper presents a story without an end. Implementation of TC2K at Pennsylvania State University at Harrisburg is ongoing, but the plan that got us here appears in hindsight to have been practical and generally effective. We have essentially accomplished the following:

- Established an atmosphere of awareness by educating faculty and staff on the fundamentals of continuous outcomes and objective assessments and evaluation and iterative program improvement.

"Proceedings of the 2003 American Society for Engineering Education Annual Conference \& Exposition Copyright $(\odot)$ 2003, American Society for Engineering Education” 
- Established a process used initially by faculty to develop and subsequently to mesh program outcomes and objectives with guidelines provided by ABET accreditation criteria. The process included identification of appropriate program constituencies that have a reasonable tie to the content of the programs and the expected skills, knowledge, and capabilities of its graduates. The process included development of subsequent surveying techniques to solicit both input to and approval of program goals by the constituencies.

- Developed and are commencing with the systematic implementation of program level assessment strategies, cross-referencing program outcomes and objectives to courses in the curriculum, identifying specific targets of opportunity for assessment and ensuring inclusion of program goals within course instruction; developing tools and systemic methodologies that support both objective and subjective assessment at multiple intervals during and after a student completes the program.

- Applying evaluation metrics to compare actual accomplishments to expected performance levels and to provide a basis for future planning to either reinforce success or to improve deficiencies.

Our internal assessments of the process indicate that we still have some room for improvement, but perhaps in the modern era of mandated "continuous improvement" that is not all bad.

\section{Bibliography:}

1. ABET Faculty Workshop for Program Improvement (January, 2002), sponsored by ABET Education and Information Services. The workshop prepared faculty participants for outcomes-based accreditation based on deliberate development of program goals, objective, and outcomes that collectively provide a framework for continuous assessment and improvement in education. Work based on application of Engineering Criteria 2000 and Technology Criteria 2000 (TC2K).

2. ABET TC2K Program Evaluator Training (June, 2002), sponsored by ABET Education and Information Services during the 2002 American Society for Engineering Education Annual Conference \& Exposition.

3. "Assessment to Improve Learning," (May, 2002), Summer Teaching Academy Workshop sponsored by the Teaching \& Learning Consortium, The Pennsylvania State University.

4. "Criteria for Accrediting Engineering Technology Programs, Effective for Evaluations During the 2002-2003 Accreditation Cycle.” (2002). Technology Accreditation Commission, Accreditation Board for Engineering and Technology, Inc.

5. Lookadoo, James A., Steve M. Hefley, and Randy Winzer (2002). "Reformatting an EET Program For TAC of ABET TC2K." Proceedings of the 2002 American Society of Engineering Education Annual Conference and Exposition, American Society for Engineering Education.

"Proceedings of the 2003 American Society for Engineering Education Annual Conference \& Exposition Copyright (C) 2003, American Society for Engineering Education " 
6. Nadler, D. A. (1988). "Concepts for the Management of Organizational Change." Readings in the Management of Innovation, Michael Tushman and William Moore, eds., Harper Business, New York.

7. Wankat, Phillip C. and Frank S. Oreovicz, 1993, Teaching Engineering, McGraw-Hill, Inc., New York.

DR. DAVID S. COTTRELL is an Assistant Professor in the School of Science and Engineering Technology at Pennsylvania State University at Harrisburg. He graduated from the United States Military Academy in 1978 and retired in 2000 after 22 years of service with the US Army Corps of Engineers.

Studies at Texas A\&M University resulted in an MS Degree in Civil Engineering in 1987 and a $\mathrm{PhD}$ in 1995. He is a registered Professional Engineer and has taught courses in statics, dynamics, mechanics of materials, graphic communications, and construction planning, scheduling, estimating, and management. 
Appendix: Structural Design and Construction Engineering Technology Program Outcomes listed according to Bloom's Taxonomy of Education Objectives.

\section{Statements describing what our students are expected to know and be able to do by the time of graduation. Our graduates will demonstrate:}

Basic Knowledge, Comprehension, and Appl ication*:

1. An appropriate mastery and ability to apply c urrent knowledge, techniques, skills, and modern professional engineering $t$ ools and adapt to emerging applications of mathematics, science, engineering, and techn ology. (1a) (1b)

2. An ability to identi fy, formulate, analyze, and apply basic technical concepts to solve technical, construction pr oblems involving hydraulics and hydrology, geo technics, structures, construction scheduling, an d management, and construction safety. (B.e) (1f)

3. The capability of utilizing modern in struments, methods and techniques to implement construction contracts, documents, and codes. (A.a)

4. The capability of utilizing m odern surveying methods for construction layout. (A.c)

5. The capability of determining forces and stresses in elementary structur al systems. (A.d)

6. The capability of estimating material quant ities and costs. (A.e)

7. The capability of employing productivity software to solve technical problems. (A.f)

8. The capability of performing economic analyses and cost es timates related to design, construction, and ma intenance of systems in the construction technical specialties. (B.b)

9. The capability of selecting appropriate construction $m$ aterials an $\mathrm{d}$ practices. (B.c) Analysis and Synthesis*:

10. An ability to conduct la boratory experiments an $d$ to critically analyze, interpret an $d$ apply exper imental results to impr ove processes. (1c)

11. An ability to apply creativity in structural design engineerin $g$ of systems, components, or processes appropriate to pr ogram objectives. (1d)

12. The capability of producing and utilizin g design, construction, and operations documents. (B.a)

13. The capability of performing standar $d$ analysis and design in at least one recognized technical specialty within construction engineerin $g$ technology that is appropriate to the goals of the program. (B.f)

Evaluation and Judgmen $t^{*}$ :

14. An ability to function effectively on multi-disciplin ary teams. (1e)

15. An ability to communicate effectively. (1g)

16. A recognition of the need for, and an abili ty to engage in lifelong learnin g. (1h)

17. An ability to understand professional, ethical, and social responsibilities. (1i)

18. A respect for diversity and a level of know ledge necessary to understan $d$ the impact of engineering solutions in ligh $\mathrm{t}$ of contemporary professional, societal and global issues. (1j)

19. A commitment to quality, timeliness, and continuous improvement. (1k)

20. The capability of evaluating $m$ aterials and meth ods for construction projects. (A.b)

*Note: B. S. Bloom 's Taxon omy of Education Objectives defines these six major cat egories of the cognitive domain. Taken from Teaching Engineering by Philip C. Wankat an d Frank S. Oreovicz, Mcgraw Hill, Inc., 1993.

"Proceedings of the 2003 American Society for Engineering Education Annual Conference \& Exposition Copyright @ 2003 , American Society for Engineering Education” 